\title{
FORMAÇÃO INICIAL DE PROFESSORES DE MATEMÁTICA E TECNOLOGIAS DIGITAIS: ELABORAÇÃO DE UMA ANÁLISE DO CONHECIMENTO
}

\author{
Filipe Sarmento Barreto ${ }^{1}$; Janilse Fernandes Nunes ${ }^{2}$
}

\section{RESUMO}

O presente trabalho constitui-se de um recorte da elaboração do Estado do Conhecimento de uma tese de Doutorado, ainda em andamento, vinculada ao Programa de Pós-Graduação em Ensino de Ciências e Matemática da Universidade Franciscana. O objetivo do artigo é compreender a definição de Estado do Conhecimento, apresentar suas etapas e sua realização para um dos descritores definidos para seu desenvolvimento, com base nas etapas propostas por Romanowski (2002). Para o primeiro descritor, "Tecnologias nos Currículos de Formação Inicial em Matemática", a busca realizada resultou em duas teses com aproximações pertinentes: Dalla Nora (2020) e Silva (2018). Ambas contribuirão com referenciais teóricos e reflexões a serem incorporadas à tese.

Palavras-chave: Currículo; Estado do Conhecimento; Licenciatura em Matemática.

Eixo Temático: Educação, Cultura e Comunicação.

\section{INTRODUÇÃO}

O presente trabalho é um recorte da etapa de Estado do Conhecimento de uma tese de Doutorado que investigará como os cursos de Licenciatura em Matemática das instituições de ensino superior federais do estado do Rio Grande do Sul, implantaram as diretrizes vigentes em seus currículos, no que tange às tecnologias digitais. No desenvolvimento da pesquisa, uma das etapas iniciais compreende a elaboração do Estado do Conhecimento, na qual se faz um levantamento dos trabalhos já realizados sobre a temática da tese ou temas relacionados. Sendo assim, o objetivo deste trabalho é compreender a definição de Estado do Conhecimento, apresentar suas etapas e sua realização para um dos

\footnotetext{
${ }^{1}$ Universidade Franciscana. f.barreto@ufn.edu.br.

${ }^{2}$ Universidade Franciscana. janilse@ufn.edu.br.
} 
descritores definidos.

\section{ESTADO DO CONHECIMENTO}

Desenvolver uma pesquisa consiste numa busca por respostas aos problemas propostos, tratando-se de um procedimento racional e sistemático que se desenvolve em várias fases, com base em conhecimentos existentes e apoiada em técnicas, métodos e procedimentos científicos. (GIL, 2002). Sendo assim, várias pesquisas diferentes podem debruçar-se sobre o mesmo problema a tentar ser solucionado, cada uma adotando métodos e referenciais teóricos distintos, além da trajetória do pesquisador, que também pode interferir.

Considerando, então, as várias possibilidades de caminhos a seguir para elaborar e desenvolver uma pesquisa, faz-se necessário buscar e analisar o que já foi desenvolvido, a fim de evitar dar andamento a temáticas recorrentes e, quando isso ocorrer, optar por metodologias diferentes para responder questões que ainda ficaram em aberto sobre o tema. Levando em conta tais preocupações, essa busca consiste na verificação do Estado do Conhecimento, aqui diferenciada do Estado da Arte.

De modo amplo, o Estado da Arte constitui-se como um mapeamento do conhecimento já elaborado, destacando o enfoque dado, recorrência dos assuntos e possíveis lacunas ainda existentes. Não se trata, no entanto, de uma mera identificação, mas de uma análise cuidadosa, categorizando os achados. A base de consulta pode incluir trabalhos provenientes de investigações feitas para teses de doutorado ou dissertações de mestrado, bem como artigos publicados em periódicos e eventos. (ROMANOWSKI; ENS, 2006).

Apontando para um entendimento semelhante, porém adotando o termo estado do conhecimento, Morosini e Dalla Corte (2018, p. 99) explicam que "entende-se por estado do conhecimento o acesso ao conhecimento já existente, aos conceitos e princípios fundantes que já estão estabelecidos, ou seja, a produção de conhecimento que tem início tendo por base a busca de informações sobre aquilo que já foi produzido anteriormente." 
Diante da diferenciação de termos que, em síntese, descrevem a mesma ação, de buscar aquilo que já está posto sobre um determinado tema, procurou-se um ponto de divergência entre as terminologias. Sendo assim, para o desenvolvimento da pesquisa, será considerada a definição mencionada de Romanowski e Ens (2006) para Estado da Arte e, para Estado do Conhecimento, a ideia de que se constitui de um estudo em apenas um setor das publicações sobre o assunto em debate.

Considerando, então, que a distinção entre as etapas de construção dos Estados da Arte e do Conhecimento dá-se apenas pela limitação imposta às fontes de busca, serão tomados por base os procedimentos propostos por Romanowski (2002, p. 15-16)

\footnotetext{
- definição dos descritores para direcionar as buscas a serem realizadas; - localização dos bancos de pesquisas, teses e dissertações, catálogos e acervos de bibliotecas, biblioteca eletrônica que possam proporcionar acesso a coleções de periódicos, assim como aos textos completos dos artigos;

- estabelecimento de critérios para a seleção do material que compõe o corpus do estado da arte;

- levantamento de teses e dissertações catalogadas;

- coleta do material de pesquisa, selecionado junto às bibliotecas de sistema COMUT ou disponibilizados eletronicamente;

- leitura das publicações com elaboração de síntese preliminar, considerando o tema, os objetivos, as problemáticas, metodologias, conclusões, e a relação entre o pesquisador e a área;

- organização do relatório do estudo compondo a sistematização das sínteses, identificando as tendências dos temas abordados e as relações indicadas nas teses e dissertações;

- análise e elaboração das conclusões preliminares.
}

E a partir dessas etapas supracitadas, que o estudo será organizado na pesquisa, conforme consta na metodologia.

\section{METODOLOGIA}

Com base nas etapas propostas por Romanowski (2002), a primeira compreende a escolha dos descritores utilizados para a realização das buscas, sendo eles: "Tecnologias nos Currículos de Formação Inicial em Matemática", “Tecnologias na Formação Inicial em Matemática", "Currículos de Formação Inicial em Matemática”, "Tecnologias nos Currículos de Formação Inicial”, “Tecnologias nos Currículos de Matemática". Tais descritores irão subsidiar as temáticas principais 
desenvolvidas na tese e foram definidos com base na interrelação entre os temas abordados, a fim de aproximá-los do desenvolvimento do Estado do Conhecimento.

A segunda etapa abrange a definição dos bancos ou bibliotecas para realização das buscas das teses a serem analisadas. A pesquisa e acesso aos materiais foram feitos por meio do portal eletrônico da Biblioteca Digital Brasileira de Teses e Dissertações (BDTD), onde são disponibilizadas teses e dissertações produzidas nas instituições de ensino e pesquisa brasileiras. A opção por utilizá-la como fonte de consulta apoia-se em seu acesso livre e gratuito e no volume de publicações disponíveis.

A terceira etapa do procedimento para levantamento do Estado do Conhecimento consiste no estabelecimento dos critérios de seleção dos materiais que comporão o corpus. Para os descritores supramencionados, a busca deve consistir nos seguintes critérios: ser um trabalho apresentado no formato de tese; no período de 2018 a 2021; e desenvolvido junto a cursos de licenciatura em Matemática.

A quarta etapa consiste na parte prática para a realização do levantamento dos dados para a constituição da visão panorâmica apresentada no Estado do Conhecimento, que é pautada em pesquisas do tipo tese, organizada em planilha, a partir dos critérios. Para tanto, realizou-se a pesquisa dos descritores no portal da BDTD, que utilizou os critérios definidos (tese de doutorado e período) para delimitar as buscas. Foi usada a ferramenta de exportação em planilha, disponibilizada pela plataforma; os resultados foram baixados e, posteriormente, selecionados aqueles escritos a serem detalhados, com base em seu título.

A quinta etapa diz respeito à realização da coleta de dados e ocorreu juntamente com a sexta etapa, onde foram buscadas e detalhadas, uma a uma, as teses selecionadas anteriormente. A fim de organizar o desenvolvimento do trabalho e sintetizar as informações, foi elaborado um quadro, cujo preenchimento deu-se a partir da leitura das teses selecionadas, considerando seu título, palavras-chave, tipo de pesquisa, objetivos, autores citados, citações e referências.

A sétima etapa configura-se pela escrita do relatório com base nas teses selecionadas e no quadro elaborado na sexta etapa, onde são descritos os 
principais referenciais teóricos observados, bem como possíveis relações e contribuições para o desenvolvimento deste trabalho. A finalização da escrita do Estado do Conhecimento dá-se pela análise e elaboração das conclusões proporcionadas pela etapa anterior, descrevendo um panorama geral sobre os trabalhos analisados.

\section{RESULTADOS E DISCUSSÕES}

Para a exposição dos resultados preliminares, consideram-se os resultados da pesquisa realizada pelo descritor "Tecnologias nos Currículos de Formação Inicial em Matemática", realizada no portal da BDTD. A busca, que levou em conta os critérios definidos inicialmente, retornou dezessete resultados, dos quais dois foram selecionados para detalhamento.

A primeira tese, de Dalla Nora (2020), intitulada "Formação inicial de professores de Matemática no âmbito das tecnologias digitais de informação e comunicação", tem por objetivo analisar de que modo alunos de um curso de licenciatura em Matemática operam com as Tecnologias Digitais de Informação e Comunicação (TDICS), no âmbito do estágio docente, partindo de sua formação inicial. Para tanto, foi realizado um grupo focal com alunos em etapa de realização dos estágios supervisionados e analisados os discursos observados durante os encontros com esses sujeitos, recorrendo-se ao processo de desnaturalização proposto por Foucault. Além disso, foram considerados, também, como fonte de pesquisa, documentos reguladores do curso de Matemática (como o Projeto Pedagógico de Curso, diretrizes vigentes e BNCC), para identificar como se justifica o uso das TDICS na perspectiva do estágio.

Dos documentos e discursos analisados para a pesquisa, emergem duas dimensões de análise: a primeira revela um discurso salvacionista e, ao mesmo tempo, de desigualdade de acesso às TDICS e de dispersão quando utilizadas (não favorecendo, assim, a aprendizagem), constituindo-se, assim, em um paradoxo. Já na segunda dimensão observada, a pesquisadora tece considerações acerca da postura docente diante das TDICS, destacando a importância da formação inicial, visto que licenciandos participantes dos grupos focais ressaltaram o espaço da 
graduação como um ambiente formativo e propício para a ressignificação dos saberes.

A segunda tese analisada, correspondente ao descritor "Tecnologias nos Currículos de Formação Inicial em Matemática", intitula-se "Vídeos de conteúdo matemático na formação inicial de professores de Matemática na modalidade a distância", de autoria de Silva (2018). Inserindo-se, também, no espaço dos estágios supervisionados, porém de um curso de licenciatura em Matemática na modalidade de Educação a Distância, o autor investiga as potencialidades que a produção e o uso de vídeos abordando conteúdos matemáticos propiciam aos alunos desse curso, mediante entrevistas, questionários e sua observação participante no ambiente virtual de aprendizagem onde ocorriam as aulas.

Os vídeos (e a produção deles, pelos estudantes estagiários) são compreendidos, no contexto da pesquisa, como um recurso alternativo às práticas educativas tradicionais, contribuindo na atuação do professor e na aprendizagem do estudante. Além disso, entende-se que sua criação pode exteriorizar os saberes desenvolvidos pelos estagiários durante sua trajetória enquanto estudantes e futuros professores de Matemática.

Da busca e análise por dissertações e teses que abordassem a utilização de vídeos chega-se à perspectiva de Borba e Villarreal (2005) de seres-humanos-commídias, no sentido de extrapolar a dicotomia entre seres humanos e tecnologias e a relação com a produção de conhecimentos. A pesquisa permite concluir, então, que os sujeitos da pesquisa (licenciandos do curso de Matemática) assistem vídeos com conteúdo matemático, a fim de auxiliar os estudos nas mais variadas componentes curriculares do curso, além de utilizarem em suas aulas na Educação Básica.

As duas teses detalhadas, referentes ao primeiro descritor, assemelham-se pelo seu desenvolvimento ter ocorrido no espaço do estágio supervisionado curricular de cursos de Licenciatura em Matemática, contribuindo, assim, como estudos no âmbito da formação inicial de professores de Matemática. A primeira pesquisa contribui no sentido de atentar se a implementação das diretrizes nos cursos a serem analisados convergem para alguma das dimensões percebidas pela autora. A segunda tese analisada agrega a ideia de seres-humanos-com-mídias, 


\section{OUFN}

podendo ser uma concepção incluída na elaboração da tese, bem como verificado se essa abordagem é feita nos cursos de licenciatura que serão analisados.

Para fins de uma análise quantitativa acerca das produções acadêmicas no portal da BDTD, no período de 2018 a 2021, foi elaborado um gráfico com a quantidade de teses encontradas a partir do descritor desta pesquisa, conforme Gráfico 1.

Gráfico 1: Descritor "Tecnologias nos Currículos de Formação Inicial em Matemática"

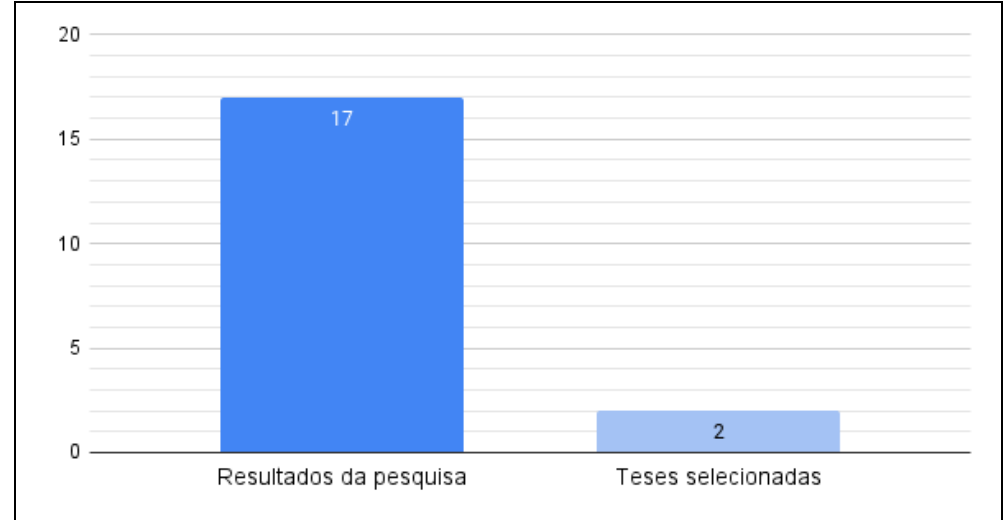

Fonte: elaborado pelo autor

O Gráfico 1 compara o total de resultados obtidos com a busca pelo descritor "Tecnologias nos Currículos de Formação Inicial em Matemática" (totalizando dezessete) com o número de teses selecionadas para detalhamento (em quantidade de duas). Esse quantitativo reduzido de trabalhos deu-se pela seleção dos títulos das pesquisas.

Também sob um viés quantitativo, o Gráfico 2 relaciona alguns dos autores referenciados nos dois trabalhos selecionados e que foram considerados pertinentes à tese de Doutorado ora em andamento. 
Gráfico 2 - Autores referenciados nas teses

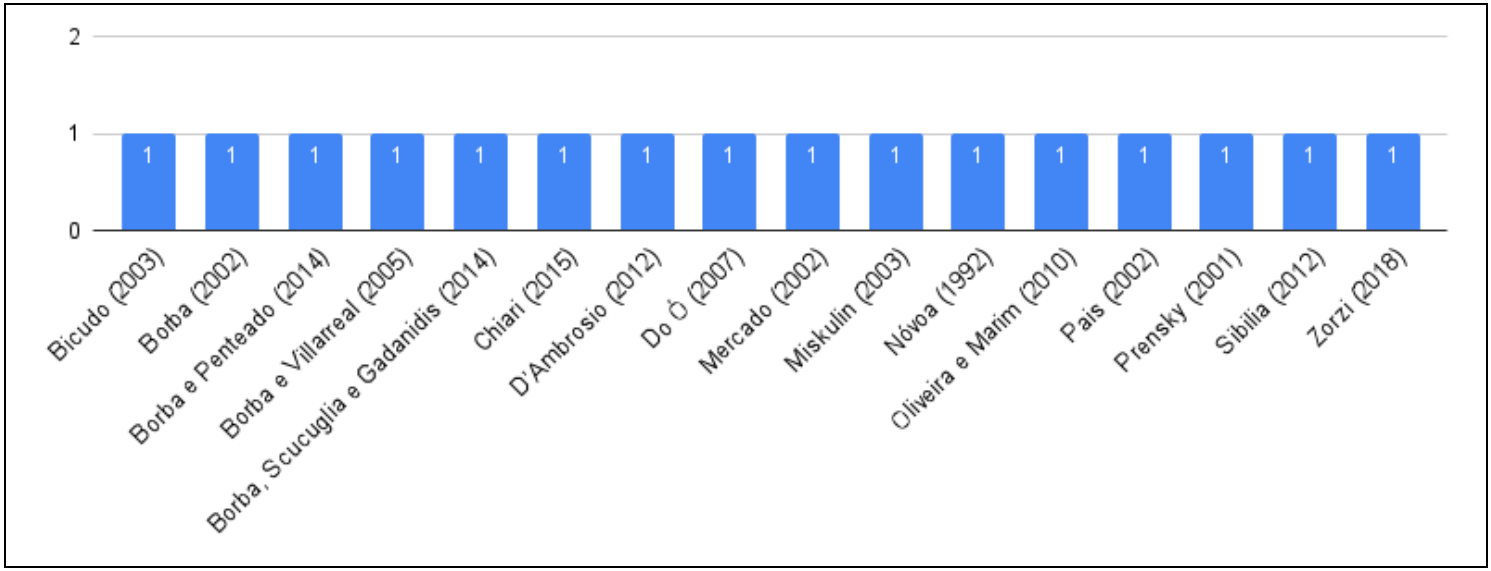

Fonte: elaborado pelo autor

Como se verifica no Gráfico 2, cada um dos autores citados para embasamento teórico consta uma vez, considerando as duas teses estudadas, o que pode indicar delineamentos teóricos diferentes em cada trabalho. No entanto, ao analisar cuidadosamente, há recorrência às ideias de Borba, porém com pesquisadores e em diferentes obras e materiais. Sendo assim, destaca-se como um referencial relevante para análise e possível embasamento teórico para a tese a ser escrita.

Dessa forma, conclui-se a análise dos achados referentes ao descritor "Tecnologias nos Currículos de Formação Inicial em Matemática" que, juntamente com os resultados dos demais descritores, permitirão ter uma visão ampla do que se tem pesquisado acerca dos temas "formação inicial de professores de matemática" e "tecnologias digitais".

\section{CONCLUSÃO}

A elaboração do Estado do Conhecimento, no desenvolvimento de uma pesquisa, constitui-se como uma importante etapa, pois proporciona uma visão ampla sobre os trabalhos realizados sobre a temática até então. Até que se chegue à etapa de elaboração do relatório conclusivo do Estado do Conhecimento, os trabalhos analisados contribuirão com referenciais teóricos ou concepções às quais se pode aderir na tese, reforçando, assim, sua relevância no ato de pesquisar. Os resultados das teses analisadas devem considerar, de modo semelhante como foi 
realizado para o primeiro descritor, possíveis aproximações teóricas e contribuições reflexivas.

\section{REFERÊNCIAS}

BORBA, M. C.; VILLARREAL, M. E. Humans-with-Media and the Reorganization of Mathematical Thinking: Information and communication Technologies, Modeling, Experimentation and Visualization. New York: Springer, v. 39, 2005.

DALLA NORA, M. Formação inicial de professores de Matemática no âmbito das tecnologias digitais de informação e comunicação. 2020, 164 p. Tese (Programa de Pós-Graduação em Educação) - Universidade do Vale do Rio dos Sinos, São Leopoldo, $2020 . \quad$ Disponível em: http://www.repositorio.jesuita.org.br/handle/UNISINOS/9513. Acesso em: 25 set. 2021.

GIL, A. C. Como elaborar projetos de pesquisa. 4.ed. São Paulo: Atlas, 2002.

MOROSINI, M. C.; DALLA CORTE, M. G. Teses e realidades no contexto da internacionalização da educação superior no Brasil. Revista Educação em Questão, v. 56, n. 47, p. 97-120, abr. 2018. Disponível em: https://periodicos.ufrn.br/educacaoemquestao/article/view/14000/9321. Acesso em: 23 set. 2021.

ROMANOWSKI, J. P; ENS, R. T. As pesquisas denominadas do tipo "estado da arte" em educação. Revista Diálogo Educacional, [S.I.], v. 6, n. 19, p. 37-50, jul. 2006. Disponível em: https://periodicos.pucpr.br/index.php/dialogoeducacional/article/view/24176. Acesso em: 23 set. 2021. 


\section{Q UFN}

ROMANOWSKI, J. P. As licenciaturas no Brasil: um balanço das teses e dissertações dos anos 90. Tese (Doutorado) - Faculdade de Educação da Universidade de São Paulo, São Paulo, 2002.

SILVA, S. R. P. da. Vídeos de conteúdo matemático na formação inicial de professores de Matemática na modalidade a distância. 2018, 248 p. Tese (Programa de Pós-Graduação em Educação Matemática) - Universidade Estadual Paulista, Rio Claro, 2018. Disponível em: https://repositorio.unesp.br/handle/11449/180385. Acesso em: 26 set. 2021. 